\title{
Analysis on the Role of Service Providers in Promoting the Development of Rural E-commerce --- Take Luoyang Shanxun Company as an Example
}

\author{
Ye Xiumin \\ Center for Informatization Study of Chinese Academy of Social Sciences, Beijing, China \\ Email address: \\ xmye@cass.org.cn \\ To cite this article: \\ Ye Xiumin. Analysis on the Role of Service Providers in Promoting the Development of Rural E-commerce --- Take Luoyang Shanxun \\ Company as an Example. International Journal of Economics, Finance and Management Sciences. Vol. 9, No. 3, 2021 , pp. 106-111. \\ doi: 10.11648/j.ijefm.20210903.12
}

Received: February 1, 2021; Accepted: May 10, 2021; Published: May 24, 2021

\begin{abstract}
China's rural e-commerce has developed rapidly, in recent years, but there are still many bottlenecks restricting the development, such as the imbalance of regional development, the lack of e-commerce talents, the difficulty in selling agricultural product and so on. Based on the field investigation and in-depth interview of Taobao villages in Henan Province, this paper summarizes the experience of the intermediary business represented by Luoyang Shanxun company in promoting the development of Taobao village. In the rural areas without the development gene of rural e-commerce, through the "government + service provider" model, professional service providers can help the local government to carry out the overall planning, train talents and incubate e-businesses, and assist farmers' e-businesses in villages to solve the practical problems encountered in the operation of e-stores. The role of service providers in the development of rural e-commerce is worthy of recognition, and its advanced experience is worth promoting and learning. In the areas where the spontaneous growth ability of rural e-commerce is weak, it is necessary to introduce third-party professional service institutions. Through the empowerment of professional service providers, help villagers master the skills of e-commerce entrepreneurship and employment as soon as possible, and solve the difficult problems in rural e-commerce operation. Summing up and promoting the experience of professional service providers is helpful to the development of rural e-commerce in China.
\end{abstract}

Keywords: Rural E-commerce, Service Providers, Agricultural E-commerce

\section{Introduction}

Rural e-commerce has developed rapidly in China with the joint efforts [1] of the government [2], the platform and the new farmers. China's rural online retail sales reached 1.37 trillion yuan in 2018 , a year-on-year increase of $30.4 \%$. The development of e-commerce in rural areas also promotes the rapid development of Taobao village [3], and drives farmers to return home to start businesses and get rid of poverty $[4,5]$. Taobao villages have grown out of nothing since 2009. As of 2018, 3202 Taobao villages have been found in China.

Most of the Taobao villages which are self-generated and grow up [6]. However, many rural areas do not have the gene of spontaneous growth, which is reflected in the lack of leaders, the lack of characteristic products suitable for online trading, the lack of business atmosphere, and the inconvenience of logistics. In this case, we need a very professional rural e-commerce service providers, as the fourth force, to participate in the construction of rural e-commerce, to carry out scientific planning [7], integrate resources, train talents, incubate guidance, and solve pain problems [8].

There are still some problems in the development of rural e-commerce [9, 10], which need to be solved urgently [11]. These problems mainly include: unbalanced development of rural e-commerce, backward understanding of e-commerce, lack of high-end e-commerce operation talents, lagging construction of rural e-commerce supporting service system, lack of leading enterprises and well-known brands, and difficulties in agricultural products upgrading [12, 13]. It is more particularly difficult for the rural e-commerce to develop and reach the identification standard of Taobao 
village. Although Taobao village has a ten-year development history, the number of Taobao villages is still negligible. $99.54 \%$ of the administrative villages in China are not Taobao villages. Most of the Taobao villages that have been identified are self- generated and growing up. However, many rural areas do not have the gene of spontaneous growth, which is reflected in the lack of leaders, the lack of characteristic products suitable for online trading, the lack of business atmosphere, and the inconvenience of logistics. In this case, we need a very professional rural e-commerce service providers, as the fourth force, to participate in the construction of rural e-commerce, to carry out scientific planning, integrate resources, train talents, incubate guidance, and solve pain problems [14].

E-commerce professional service providers play an enabling role: help farmers master the ability to use e-commerce, promote the docking of agricultural products and rural characteristic products with the global market, promote the transformation of rural economic and social development mode, and promote the construction of beautiful countryside. E-commerce professional service providers are still the backbone of bridging the information gap and e-commerce gap in some rural areas.

It is found that the rural e-commerce in Henan Province started later than the other provinces in the east of China, but the rural e-commerce in Luoyang and Nanyang is in full swing. According to the traditional view, some products that are not suitable for online trading, such as Tang Sancai, peony paintings, goldfish, vegetables and fruits, are sold on the Internet. 11 Taobao villages were found in Luoyang in 2018, including Pingle peony painting Taobao village, ChaoyangTang SancaiTaobao village and Songzhuang fresh fruits and vegetables Taobao village in Mengjin County of Luoyang City. The three characteristic Taobao villages were integrated into one, and the Mengjin model also won the "top ten cases of e-commerce promoting rural revitalization". Huang shaomeng from Pingle peony painting Taobao Village won the title of excellent leader of Taobao village in 2018. There are 165 peony painting online stores in Pingle village, with online transaction volume exceeding 55 million yuan. Peony paintings are not only popular in China, but also exported to Singapore, Malaysia and other countries. Songzhuang also has more than 150 characteristic agricultural products Taobao shops, with online transaction volume of 26 million yuan. Its characteristic products such as pocket watermelon, flat peach and grape are exported to Guangdong, Jiangsu and Shandong through e-commerce channels. The online sales of carp in Xiangzhaivillage of Zhenping county exceeded 15 million yuan in 2018, driving nearly 1000 poor households around to become rich, with an average income increase of more than 3000 yuan.

Luoyang rural e-commerce achievements can should be attributed to an e-commerce professional service provider named Shanxuncompany. Shanxuncompany is the fourth professional force to promote the development of rural e-commerce in Luoyang. The analysis of the operation experience of service providers represented by
Shanxuncompany is helpful to summarize the positioning and role of service providers in the rural e-commerce ecology, promote the solution of the bottleneck problems in the development of rural e-commerce, and promote the rapid development of rural e-commerce in China.

\section{Strategic Planning to Solve the Problem of What to Do}

\subsection{Incubation Through Training}

Shanxuncompany's main business model is "government + service provider". The team would spend more than ten days in the village for in-depth interview and investigation before cooperating with the local government. The survey covers village culture, local product characteristics, villagers' composition, transportation and logistics, e-commerce development and constraints. After the investigation, the whole team has a basic understanding of how to develop the local rural e-commerce. After in-depth analysis and discussion, a strategic plan of e-commerce development with the characteristics of the village is formed. This plan includes the annual goals of this year and the next year, the positioning of trading products, the entry point of marketing, how to mobilize and train villagers, how to improve infrastructure, and how to solve the bottleneck problems in development step by step.

After identifying the target, the next step is to excavate and integrate the local characteristic product resources, and make an article from the product length and breadth. Firstly, the team will build high-end brands and products in terms of product quality. According to the characteristics of products, master product inheritors such as Tang Sancai, peony painting and jade carving are packaged on the Internet platform to create high-quality brands and high-value products. And through the combination with characteristic culture, drive the sales of middle and low-end products. Secondly, based on the local cultural advantages, expand the length of the industrial chain. With the help of the local government's to build the Tang Sancai Town, the hometown of peony painting, and the jade culture and creative industry center, give full play to the master effect and brand effect, and build an industrial chain integrating exhibition, manufacturing, experience, purchase, service, storage and distribution. By extending the industrial chain, providing additional services, creating more employment opportunities and promoting industrial transformation and upgrading. Finally, increase the breadth of product categories. Based on Tang Sancai, they expanded the sub categories, increased the categories of decorations and pendant, and promoted sales through product innovation.

Taking Xiangzhai village, Houji Town, Zhenping county as an example, Shanxun company found that the characteristic industry of the village is the well-known goldfish breeding industry after investigation. Goldfish farmers began to appear in the village since the 1980s. After the leading farmers got rich, other villagers began to imitate 
and learn. Now $80 \%$ of the villagers are doing fish related work, with an annual output value of more than 80 million yuan. The aquaculture water area of Houji town is over $10000 \mathrm{mu}$, and more than 120 valuable varieties such as Zhudingziluopao have been developed, with an annual output of 50 million fish. It is the largest goldfish breeding base with the most varieties in Central Plains. One of the most distinctive is the koi breeding industry, accounting for about $60 \%$ of the national share, which is the largest Koi breeding base in China. Zhenping county was officially named "the hometown of goldfish in China"by the Organizing Committee of the hometown of Chinese specialties in 2003. With such a good industrial advantage, Shanxuncompany decided to take goldfish products online sales as a breakthrough to create a goldfish featured Taobao village.

Similarly, around the development idea of "one town, one village, one product", Shanxuncompany has built Taobao village with Tang Sancai, peony painting and fruit and vegetable products as the main products according to the industrial characteristics of Chaoyang Town, Pingle town and Songzhuang town. With the help of the Internet, local characteristic products will be sold to the global market, and the popularity of characteristic products will be expanded. These characteristic products expand from offline sales to online sales, broaden the scope of product marketing, increase the scope of global market sales, promote sales, increase the income of farmers, and promote the transformation and upgrading of rural economy.

\subsection{Targeted Layered Services}

Shanxuncompany's first job after entering the village is training, hand in hand to teach farmers how to open online stores. According to the past experience, there is a big difference between the individual ability of farmers' online merchants and the operation of online stores. If a unified incubation and training, the effect is not ideal. As a result, Shanxuncompany classifies the network operators in each village and provides targeted services for different types of network operators. Shanxuncompany establishes a background service system, in order to get through the background of each online store and tracking analysis the online store business data. According to the operation data, the shops in the village are divided into three categories: benchmark shops, key shops and active shops. Benchmarking stores refer to the stores with distinctive products or brands and high turnover. Key stores refer to the stores with increasing trading volume and great development potential. Active shop refers to the shop where the owner logs in every day and has a certain transaction volume.

For different types of stores, Shanxuncompany adopts targeted layered service strategy. Take Chaoyang Tang Sancai as an example, the online stores of several masters are defined as benchmark stores. The special person of shanxun company's service station in the village conducts one-to-one counseling to help the online stores carry out decoration design. Through the introduction of Sancai culture and Master inheritance stories, the online stores shape master brands and establish high-end product images. For the key stores, the village service station analyzes the operation problems and designs the growth plan; in addition, it provides on-site guidance for the key and difficult problems. For active stores, in addition to group centralized training, we also regularly call on the person in charge of online stores to give special guidance on common problems such as marketing, web design, packaging and customer service. Chaoyang has formed 15 benchmark stores and 35 active stores now.

\section{Integrate Resources to Construct Supporting Service System}

The healthy development of rural e-commerce must build a perfect supporting service system. Shanxuncompany integrates resources in the following aspects to ensure the smooth development of e-commerce activities.

\subsection{Integrate Government}

Integrate government resources and promote the construction of service system. The characteristic of "service provider + government" mode is that service provider and government form a joint force to form a service system supporting the development of rural e-commerce. The relevant departments of Mengjin County and Nanyang Municipal government attach great importance to the development of rural e-commerce. In order to promote the formation of Taobao village, a three-level cadre service system of county, town and village has been set up, and each level has a special leader in charge.

\subsection{Integrate the Resources of Service Providers}

Shanxuncompany will build e-commerce service station in each village to provide guarantee in organization and personnel after the development planning of Taobao village is completed. Shanxuncompany has sent about 7 staffs as a long-term team settled in each village. The team is composed of professionals from operation, art, lecturer and other positions. The main responsibilities of the team are training, incubation and home guidance, to help farmers solve the practical problems encountered in the process of opening online stores, and to improve the e-commerce service system until the real realization of the construction goal of Taobao village.

\subsection{Integrate Logistics Resources}

Logistics is an essential part of online marketing industry, and the quality of logistics distribution service is also the most important part to improve consumer satisfaction. In the early stage of the formation of Taobao village, most villages did not provide logistics services. Shanxuncompany gathers the network transaction volume of the whole village, invites larger logistics companies to enter, and gathers online business orders to negotiate the most favorable logistics price. 
After the net sales volume of the village forms a certain scale, logistics companies are attracted by the order volume and will come to the village spontaneously to provide services.

\subsection{Integrate Industry Chain Resources}

The development of Taobao village has also led to the rise and development of supporting enterprises in the industrial chain. In Pingle peony painting Taobao village, while peony painting is popular on the Internet, mounting service industry, painting paper and pigment distribution enterprises and logistics enterprises are developing rapidly. In Houji goldfish Taobao village, there have been businesses specializing in packaging bags, oxygen, and logistics express companies have begun to come to the village to solicit goods.

\subsection{Integrate Cultural Resources}

Luoyang is the ancient capital of the thirteen dynasties, with unique historical resources and Central Plains culture. Shanxun company makes full use of local cultural resources to "package and sell" local characteristic products and historical and cultural allusions, let historical and cultural speak for products, increase product added value, and promote the deep integration of "product + culture". Tang Sancai is the projection of economic, folk, cultural and technological characteristics of Tang Dynasty, which has high collection value. With the advantages of the birthplace of Tang Sancai, shanxun company, based on the "Sancai culture" brand of Chaoyang Town, integrates the Sancai culture into e-commerce operation, and takes the various innovative work of Taobao village as the breakthrough point to build a Sancai town and carry forward the Sancai culture. Pingle peony painting is also integrated with Luoyang's unique "Peony Culture Festival" to promote peony culture through painting exhibition; similarly, peony painting promotes sales with the help of flow and festival atmosphere of Cultural Festival.

\subsection{Integrate Social Resources}

Shanxuncompany has promoted the development of rural e-commerce with the external force. Experts and scholars are invited to investigate the village and make suggestions for the development of e-commerce in the village. Shanxuncompany takes the initiative to contact Taobao and other e-commerce platforms to explore a variety of cooperation with the platform, so as to find the best distribution channel of local characteristic products. Shanxuncompany also widely contacted media resources to publicize the development characteristics of Taobao villages, the new trends of farmers' Entrepreneurship and income increase, and the new changes of rural economic transformation. Through the promotion of popularity and reputation, it promotes the network sales of local characteristic agricultural products, attracts more migrant workers to return home to start their own businesses, and more social resources are also pouring in.

\section{Training and Incubation to Solve the Problem of Who Will Do It}

The core of the development of rural e-commerce is the cultivation and incentive of rural talents, that is to mobilize more farmers and returnees to participate in the network operation, and stimulate their enthusiasm for innovation and creation with the help of the Internet. The first thing for Shanxuncompany to enter each village is to organize local farmers to conduct online entrepreneurship training.

\subsection{Comprehensive Training, Let More People Master E-commerce Skills}

The key to the rapid development of rural e-commerce is to stimulate the spontaneous enthusiasm and creativity of e-commerce, so the early publicity and training work is very important. When shanxun company entered Nanshan village, Chaoyang Town, local Tang Sancai products had not been sold through network channels, and no one in the village understood e-commerce. Shanxuncompany propagated with the local village government door-to-door. The new training center was named Sanxin. 120 people attended the training in just one month. The training content includes e-commerce knowledge popularization course, online store operation process and skills, online store decoration and art, etc. In the online store operation class, the lecturers not only talks about the process of store certification, the analysis of store operation ideas, the backstage module of the seller center, but also talks about the online store page style, picture effects, copywriting planning, etc.

\subsection{Close Incubation, Providing Whole Process Tracking Service for Farmers' E-Commerce}

Online store operation needs rich business experience and in-depth understanding of the platform and market. Even if farmers open online stores, they may not make profits immediately. They need to carry out a series of down-to-earth operation and innovation. And all this needs strong self-study ability and comprehensive quality. Therefore, after the training, Shanxuncompanyalso provides incubation services for the operation of farmers' online stores. In the process of building Houji goldfish Taobao village, shanxun company formulated the " $1+2+2$ " mode. "1" represents a month for comprehensive training of basic knowledge. "2" represents two months for in-depth incubation, and the staff hand in hand teach farmers how to operate online stores to help them increase sales. The second "2" represents two months of in-depth incubation and benchmarking integration, including establishing typical online stores and providing key assistance to key online stores.

\subsection{Set up a Model and Drive More People to Start Business and Get Employment}

Online business leaders play an important leading and exemplary role in the development process of Taobao village. The founder of Shaji mode, the "three swordsmen", hands on 
the network marketing business to his relatives and friends in the same village, passing it from one to the next, promoting the fission development of the number of network merchants in their village. Shanxuncompany in operation, but also focus on mining and training network business in the excellent leader. Huang shaomeng, an online business of peony painting in Pingle Town, and Wang Mengmeng, an online business of Tang tricolor in Nanshan, are excellent leaders. Huang shaomeng of Pingle town returned to his hometown to start his own business. He was not only the first to set up an online shop to get rich, but also led the surrounding villagers to open online shops to get rich under the organization of Shanxun company, and taught the neighbors the online marketing skills of peony painting.

\section{Innovationto Solve the Problem of Development}

Although after a lot of training, the farmers often encounter a variety of problems in the actual operation of online shop. Due to the limited experience and ability, it is difficult for them to find the best way to solve the problem. Shanxuncompany is a professional e-commerce service providers. They have explored a lot of online shop operation experience, formed a complete knowledge system based on the years of practice. They also have a set of professional talent team. Service providers can help villagers to solve the operational difficulties effectively with professional service.

\subsection{Product Innovation, to Solvethe Problem of Personalized and Non-standard Goods online Sales}

Traditional goods can be sold directly on the Internet to connect with a larger market, but there may still be a problem of poor sales. Tang Sancaiproducts market space has been blocked in the network channel sales for a long time. Shanxuncompany and a group of network business representatives started repeated research, and analyzed much user feedback and background data. They found that the existing products can't meet the needs of users, and monotonous varieties, narrow application scope and high unit price are the main factors restricting the market space. A series of Tang Sancai products were innovated soon, such as Tang Sancai 12 zodiac, Tang Sancai car accessories. New products are more suitable for online sales. These products not only inherit the Tang Sancai technology and traditional culture, but also integrate the needs of modern consumers. The new products become popular soon.

\subsection{Packaging Innovation, to Solve the Problem of Unsuitable Storage and Transportation}

These characteristic products in Luoyang rural areas, such as goldfish, Tang Sancai, peony painting and agricultural products, are not suitable for warehousing and logistics. If these products want to sell well on the Internet, they must be innovated in warehousing and transportation. Shanxuncompany in each village team together with the net merchants of the village conducted a variety of experiments and exploration, and finally found a variety of solutions to storage and logistics problems. Goldfish is a living animal living in water, which has a high demand for living environment. In the initial online marketing, the fish buyers received were often dying. The staff of Shanxuncompany finally found the mode of double-layer fish bag + oxygen injection + heat preservation box after repeated practice in order to improve the storage life of fish warehouse. The packaging is not only strong, but also the weight is also reduced. As the result, the logistics cost is reduced. Moreover, the survival rate of fish is improved, and the survival period in logistics is increased from 3-4 days to 7-10 days. The improvement of packaging expanded the sales radius of goldfish, and the sales increased rapidly. In the past, the offline wholesale goldfish in Houji town was weighted by "Jin", and 100 goldfish were sold only for 100 Yuan, equivalent to 1 yuan for each fish. Now, the average price of one goldfish sold online is 20 yuan, and the product value has been greatly improved. There are 145 goldfish net merchants in the village, with annual sales of 15 million yuan.

Similarly, for fragile Tang Sancai products, Shanxuncompany assisted the Internet merchants to improve the packaging, adopting the packaging mode of "plastic air column + wooden frame + external box", reducing the loss in the transportation process. After the improvement of delivery and packaging, the agricultural products have also entered the national market through network channels. Pocket watermelon was packaged with air column, which was distributed to consumers all over the country and sold at a good price; grape was packaged with "Incubator + vacuum bag + ice bag" mode, which created a record of "zero bad fruit" in logistics delivery. The packaging of peony painting also needs innovation. The picture frame is directly changed into a round corner, the damage rate of the picture frame will be greatly reduced. A change in packaging details will significantly improve user satisfaction.

\subsection{Mode Innovation, to Solve the Problem of Traffic and Price}

Shanxuncompany also keeps pace with the market in the operation mode, and promotes "live + new retail" to take root in Taobao villages. In the home of goldfish Taobao village, it is not difficult to see such the scene that the online business introduces the name, characteristics and living habits of each fish to the fans with live broadcast APP. The subsequent goldfish auction reached a climax, with four small goldfish bidding from 20 yuan to 145 yuan. Through the auction, consumers bought their favorite goldfish, and farmers also sold them at a good price.

In the jade wholesale market of Shifosi Town, Zhenping county, the live broadcast is very popular in every market stall. Every shopkeeper has no time to greet customers. Instead, they are busy broadcasting all kinds of jade products on their mobile phones. If there are jade products that fans are interested in, the seller will show the shape and transparency of the jade in an all-round way, and help fans 
analyze the fineness of the jade. Once they see the defects, the sellers will tell the fans the location and size of the defects. In 2018, the jade wholesale market in Shifosi town sold jade products through live webcast, reaching 500 million yuan.

Songzhuang has the advantage of fruits. Shanxuncompany organizes fruit farmers to adopt the pre-sale mode in various e-commerce platforms to understand the market demand in advance and seize the market opportunity. The fruit and vegetable industry in Songzhuang town covers an area of $18000 \mathrm{mu}$, bringing together strawberry, pocket watermelon, grape, fresh peach, kiwi fruit and other characteristic agricultural products. Shanxuncompany organizes fruit growers to share planting information with each other and sell different types of fruits in different seasons. For example, all online stores sell strawberries since spring, then peaches, watermelons and grapes. Thewhole village's Internet merchants are busy till winter. Even in winter, fruit off-season, some network operators rely on network operation experience to sell local characteristic products. Mr. Ma, a villager of Songzhuang, planted six mu of peach trees. In the past, a large number of flat peaches appeared on the market during the harvest season, and the peaches could only be sold for two yuan. Online docking with the national market, the pre-sale price of fine peach can reach 8 yuan per catty. In the off-season, he opened several online stores on Taobao and Pinduoduo, and operated four treasures of the study, with thousands of yuan of business every day

\section{Summary}

Rural e-commerce helps to promote rural economic and social transformation, and promote farmers' innovation and entrepreneurship. Professional service providers has played an important role in promoting the development of rural e-commerce and become the fourth driving force. In the areas where the spontaneous growth ability of rural e-commerce is weak, it is necessary to introduce third-party professional service institutions to help local governments make overall planning, mobilize local villagers to participate in rural e-commerce, and conduct training and incubation. Through the empowerment of professional service providers, help villagers master the skills of e-commerce entrepreneurship and employment as soon as possible, and solve the pain points and difficult problems in rural e-commerce operation. Summing up and promoting the experience of professional service providers is helpful to the development of rural e-commerce in China.

\section{References}

[1] Ye Xiumin, rural e-commerce development from the perspective of building a well-off society in an all-round way, development research [J], 2018 (05).

[2] Ye Xiumin, "No absence, no offside" of the government in the development of Taobao village, information construction $[\mathrm{J}]$, 2019 (11)

[3] Ye Shaoxia. The role of e-commerce in promoting the core competitiveness of enterprises [J]. Business culture (second half month). 2012 (02).

[4] Wang Mang, Yang Xinghong., Research on the impact of rural e-commerce development on Regional Farmers' income, E-commerce [J]. 2020 (04).

[5] Chen Yuhong, An empirical analysis of the relationship between the development of rural e-commerce and the increase of rural residents' income in China -- Based on the panel data of 11 provinces and cities in the Yangtze River economic belt, Commercial economy research [J]. 2020 (04).

[6] Ye Xiumin, New trend of e-commerce integration in the future, information construction [J]. 2018 (11).

[7] Liu Junbin. Strategies for transformation and upgrading of e-commerce in small and medium-sized enterprises [J]. Economic guide. 2011 (04).

[8] Wu Qing Li. Electronic Commerce: concept, misunderstanding and future $[\mathrm{J}]$. Journal of Nanjing University of Posts and Telecommunications (SOCIAL SCIENCES). 2010 (2).

[9] Hou Yi, Research on the current situation, difficulties and Countermeasures of rural e-commerce development under the background of integration of three industries, Modern commerce [J]. 2020 (30).

[10] Fan Lili. Research on the integration development of rural e-commerce and rural industry -- Taking Haimen City as an example. New West [J]. 2019 (26).

[11] Feng Ji, On the construction of enterprise competitiveness under the condition of network economy [J]. Jiangsu business theory. 2008 (09).

[12] Xiao Peng, Xu min. Research on the development path of rural e-commerce under the background of Rural Revitalization, Industry and Technology Forum. [J].2020 (09).

[13] XuHuimin, Li Hongchang, Exploration on the development path of rural e-commerce in Liaoning Province under the background of Rural Revitalization Administrative assets and finance [J]. 2020 (06).

[14] Wang Chuanqi, Analysis on the integration of e-commerce and rural economic industry, New agriculture [J]. 2019 (02). 